\title{
TRAFFIC CONGESTION AND EFFICIENT WAYS TO DEAL WITH IT IN TBILISI, GEORGIA
}

\author{
Nino Kacharava ${ }^{1}$, Natali Maisuradze ${ }^{2}$, Nia Iskandarova ${ }^{3}$ \\ ${ }^{1}$ San Diego State University Georgia, Civil Engineering, Undergrad, Tbilisi, Georgia. \\ ${ }^{2}$ San Diego State University Georgia, Civil Engineering, Undergrad, Tbilisi, Georgia. \\ ${ }^{3}$ San Diego State University Georgia, Civil Engineering, Undergrad, Tbilisi, Georgia.
}

\begin{abstract}
Traffic Congestion has become a new version of plague for urbanized areas. Massive breakthroughs in technology, increasing in production of motorized cars, global reduction in pricesfor automobiles and the rapid population growth in Tbilisi, Georgia has led to the urgence of complete rearrangement of transportation system in the city.

As a post-Soviet Union country, Georgia has had rudiments like "Marshrutkas" (privately owned minibuses) as a primary mode of transportation. Serious research and actions started in 2019 when sustainable urban mobility plan was introduced in Tbilisi; which favors public transport and pedestrians. In the course of this project one of the main avenues was converted into complete street model and hourly parking was introduced in the city centers. However, the problem regarding traffic jams still stands. This paper contributes to analyzing current situation in Tbilisi and suggesting suitable solutions. It will cover how reversible lanes, road pricing, signalized Intersections, reserved bus lanes and parking can be adapted to Tbilisi in order to reduce traffic jams.
\end{abstract}

Key Words: traffic congestion, transportation systems, sustainable development, civilengineering.

\section{INTRODUCTION}

The world has changed, evolved, and adjusted to the massive breakthroughs, mainly in technology. Transportation system is not an exception; mass production of motorized cars, reduction in prices for automobiles, increasing opportunities for middle-income families to purchase, and the rapid population growth in cities has led to a new version of plague for urbanized areas - traffic jams.

Traffic congestion is a process when the vehicles are in excess of the particular road space available. This is an ongoing and increasing issue in transportation, especially during the rapid urbanization and population growth in cities. Traffic jams cause serious problems apart from wasting time and money; it allows more air pollution, accounts for more carbon dioxide emission, causes stress and rage in passengers, and increases the chance of car collisions since the spacing between vehicles is minimized. In modern days traffic jam is a part of everyday life; the reason for it is the combination of drivers' lack of attention, miscalculations in road design, accidents, and peak hours. It is evident that traffic congestion has enormous scales and affects everyone worldwide. However, the main question is why people try to reduce it and what the consequences are if they fail to do so. Traffic jams impact the quality of life in multiple ways; Congestion affectsmental health negatively, increases air and noise pollution, and on top of this is extremely expensive. It also alters economic productivity; reducing traffic jams is vital for the economy. It affects both private businesses and the government sector. Billions of trailers are delivering products to the destinations on the daily basis. Restaurants, stores, construction sites, cafes, malls, service centers, and manufacturing companies are all dependent on timely distribution. If productsare not delivered on time, in some cases it might cost from $100 \mathrm{GEL}$ to even 1000000 GEL moneylosses per hour/day.

While traffic congestions have various reasons, Tbilisi is the victim of traffic jams by mainly two of them: social economic factors and conventional transport planning. The process of urbanization has played a vital role. Population of Tbilisi increased; consequently, the number of commuters escalated. People from villages come to the country's center to study or to work, both accumulating number of people that current transportation planning of Tbilisi cannot handle. Citizens' road destinations are rarely random; in normal cases, they travel to work, universities, shopping centers, theatres, cinemas, or amusement parks and above all they occupy roads at the same time period.

Commuters do not analyze their decisions according to others' needs; they do not account for theirmode of transport, departure time, or travel route to others'. As a result, the road chosen by many gets overexploited and congestion is inevitable. Tbilisi is a vivid illustration of congestions caused by the inefficiency of public transport systems. According to the 2015 Tbilisi Sustainable Urban Transportation (SUT) strategy, the city has 1,118,000 inhabitants,

Received I0 November 20Z1; Received in revised form II November 20ZI; Accepted I2 December 20ZI;

Available online 28 December 20Z1;

dai: 10.4629I//CDNTECHvol5iss4pp|0-17 
and the area is $616 \mathrm{~km}^{2}$. Even though Tbilisi had a well-operating transportation system in the 1960s, after the civil war of 1991,it changed completely. "Marshrutkas" became the primary mode of transportation; they were privately owned uncomfortable minibuses with doubtful sanitation (Siradze, 2018). Tbilisi Metro system opened in 1966 and nowadays it has 2 lines with 23 stations (total of $30.2 \mathrm{~km}$ ). As public transport was not well developed and had no assigned schedule known to passengers, people preferred to save up for a private car instead. Consequently, having 1-2 cars per family got normalized in the middle-class, resulting in substantial traffic jams later. Accessibility of private cars are due to the American and Japanese websites used by most of Georgian population, where one can buy damaged cars and repair them in a much lower cost. Private cars almost never carry the amount of people it has a capacity to, usually it is a driver and a person next to them, thus it reduces the chances to the ideal situation maximizing the efficiency of transportation. If a bus takes up more space than a car, it also carries 30 times more people. The figure below shows the number of public transports (a bas and a "marshrutka") and automobiles in the whole country andin Tbilisi in particular.

Table 1. Source: Ministry of internal affairs of Georgia

\begin{tabular}{|c|c|c|c|c|}
\hline \multicolumn{7}{|c|}{$\begin{array}{c}\text { Quantity of Registered Vehicles } \\
\text { (at the end of the year, in thousands) }\end{array}$} \\
\hline & $\begin{array}{c}\text { Buses and } \\
\text { "Marshrutkas" } \\
\text { (Tbilisi) }\end{array}$ & $\begin{array}{l}\text { Automobiles } \\
\text { (Tbilisi) }\end{array}$ & $\begin{array}{c}\text { Buses and } \\
\text { "Marshrutkas" } \\
\text { (Georgia) }\end{array}$ & Automobiles(Georgia) \\
\hline 2016 & 15.6 & 373.4 & 53.4 & 973.6 \\
\hline 2018 & 15.3 & 411.5 & 53.8 & 1085.8 \\
\hline 2020 & 15.7 & 439.1 & 54.5 & 1190.1 \\
\hline
\end{tabular}

Poor development of public transportation and increased usage of private vehicles directly stimulates more congestions. Tbilisi Sustainable Urban Transport (SUT) strategy is a project created to redesign the transportation system in Tbilisi gradually, but completely. It was finalized in 2015 and implies multimodal approach. Its immediate actions were planned for 2017; 2021 yearshould have been the medium, and the long-term results will be seen in 2030. On the graph below it is visible the market shares according to the modes of transportation in Tbilisi, 2016. From the given data the city unarguably needs to take a new path towards more multimodal transportation system. Thus, the main goal of Tbilisi SUTs is to shift the focus from private cars to public transportand pedestrians' comfort by developing infrastructure for various modes of transportation.

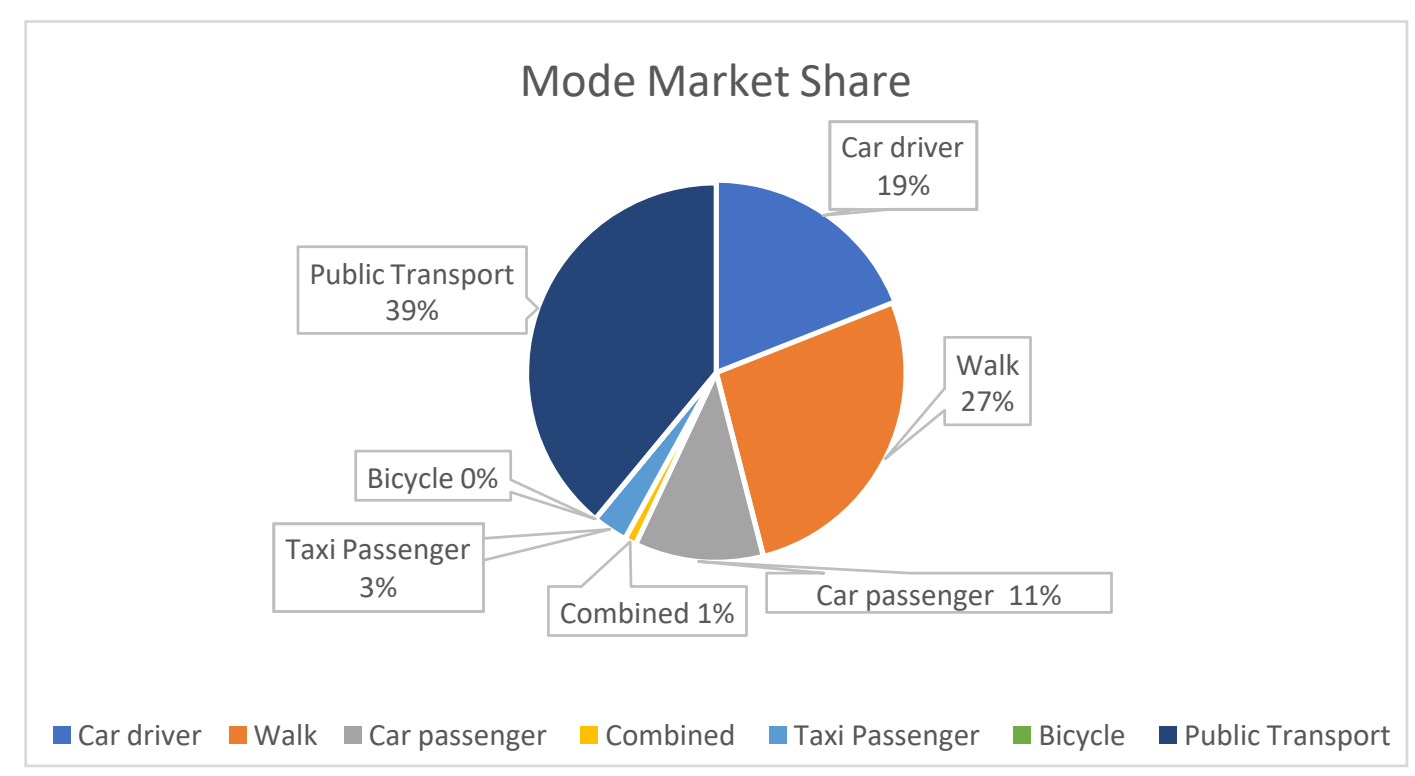

Figure 1. Source: Consulting Services for Organization of a Transportation HouseholdSurvey in Tbilisi Metropolitan Area, Systra LLC.

Received II Navember 20ZI; Received in revised farm II November 20ZI; Accepted IZ December 20ZI; 
Issues contributing to congestion in addition to already mentioned above are incorrect designs of urban roads and their maintenance. There are cases when even the traffic lanes are not marked accordingly, bus stops are designed in locations where the road is relatively narrow, or there are potholes on roads causing constraints. Unregulated parking also contributes to congestion; when the main arteries of the city do not provide enough number of dedicated parking spots, drivers haveto leave their vehicles directly on the road, significantly interfering with the traffic flow. Thus, thorough examination is needed to assess the situation in Tbilisi and plan further steps on how to solve the ongoing problem of traffic congestion in the city.

\section{METHODS}

Based on the surveys mentioned below and the personal observation of the authors in theparticular streets of Tbilisi, conclusions were made, which are discussed below.

\section{SOLUTIONS ALREADY APPLIED TO TBILISI, GEORGIA}

\section{Automated Traffic Lights}

The very first traffic light invented in 1868 in Britain was non-electronic. It used red and green gaslights to indicate stop and go, accordingly. Gradually, the technology evolved, and traffic lights became electronic. First traffic lights in Tbilisi, Georgia were installed in 1932, at the 2 major intersections - Shota Rustaveli ave. and Alexander Chavchavadze str, and Tamar Mepe ave. and Davit Agmashenebeli ave. Those traffic lights were electronic, and they were operated manually, by officers, based on their observation of traffic flows. Following the increasing rates of vehicle usage, control mechanisms at intersections have also been evolving and developing throughout theworld.

Initially developed traffic lights were pretimed. In other words, a fixed-time signal plan was used, which implies a specific amount of time dedicated for each light. Those timing decisions were made based on man-made assessments of flow (Bretherton, 1990). Such technical decision is problematic in two ways: 1.average flow patterns change over the years, and 2.flow patterns changethroughout a day (Mannering, Washburn, 1990). Not taking into account those 2 issues, leads to the even worse congestion problem, than had to be solved in the first place. In order to face these challenges, so called "smart traffic lights" were introduced.

Smart traffic lights provide optimal timing for each color of light, based on the current situation. They incorporate information obtained from several intersections and calculate the most effectivetime-intervals for each color at each intersection. SCOOT (Split Cycle Offset OptimizationTechnique) is a system of such principle, used throughout the world since the early 1980s (Robertson, 1986).

The smart traffic light system consists of observational cameras, vehicle detector installed at the intersections, analyzing/calculating software in the computer, actual traffic lights receiving information from the software and portraying the light.

Such systems are based on CFP (cycling flow profiles), which shows average one-way flow through any chosen point during each part of the cycle of upstream signal (Robertson, 1986). SCOOT is capable of measuring CFP on its own in a live regime. Vehicle detectors installed throughout the city near intersections, measure traffic flow and send the data to the computer with analyzing software. Based on the flow profiles acquired from several intersections, the software calculates and transmits optimal timings to each traffic lights, for each color in live mode. The latest versions of smart traffic lights" are not only possible to measure the flow profile, but also predict the routes and create travelling patterns. Such predictions are made using the observationalcameras.

"Smart traffic lights" were introduced in Tbilisi in 2010s and are gradually multiplying in the citysince then. Until recently, the only features that Tbilisi traffic lights had were limited to the timer for the drivers and a "press and cross" button for the pedestrians at large crossroads. In 2020 the mayor of Tbilisi, Kakha Kaladze introduced a smart traffic system, which would be started to implement in the 2021. The system includes a network of smart traffic lights, observational cameras, and controllers throughout the whole city (Business Media Georgia, 2020). In 2021 the head of the transportation department of Tbilisi city hall stated that the project would start in the end of 2021 and in 3 years the city will be fully equipped with fully smart transportation system (Business Media Georgia, 2021).

Received II November 20ZI; Received in revised farm II November Z0ZI; Accepted IZ December 20ZI;

Available online 28 December 20Z1;

dai: 10.46291//CONTECHvol5iss4pp|0-17 

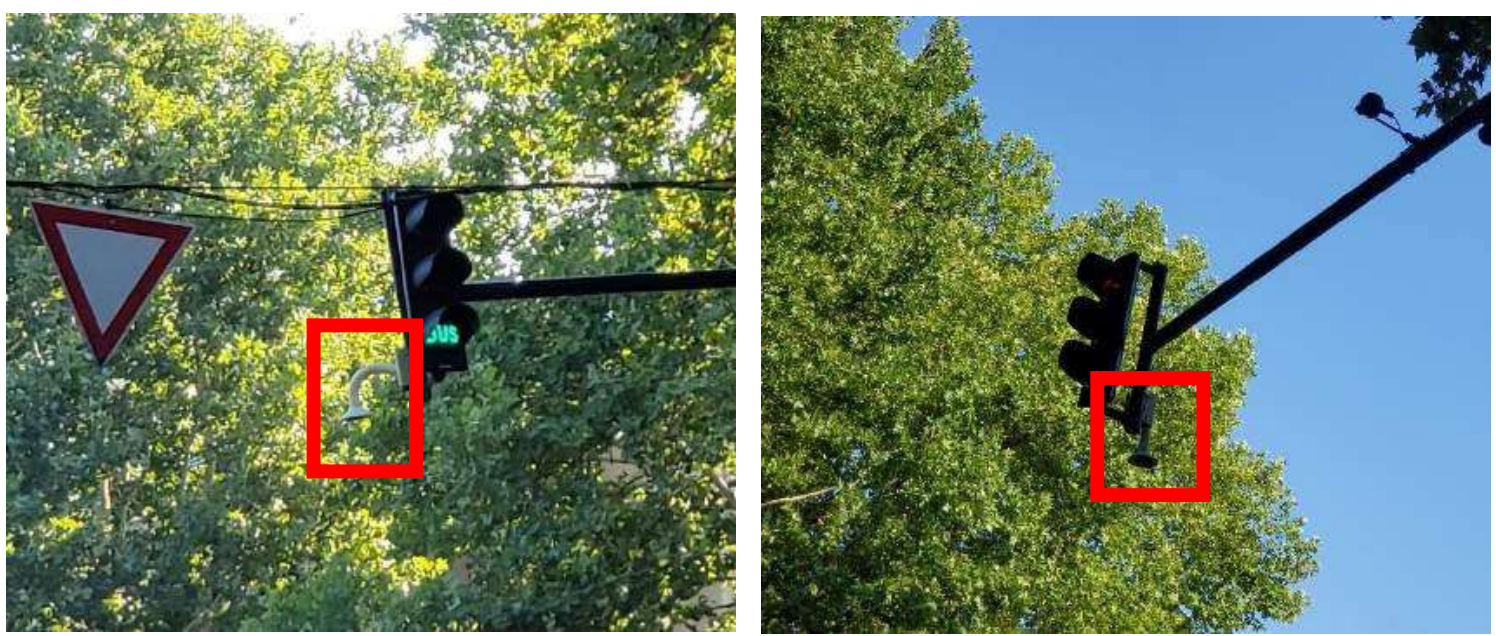

Figure 2. Vehicle detectors installed next to the traffic lights at the intersections

\section{PARKING}

It is impossible to utilize vehicle without the burden of finding a place to park it. Parking has beena serious issue, especially since the end of the 20th century, when the number of vehicles in the world has significantly increased. Uncontrolled parking can cause many serious problems, including a crucial contribution to congestion. Cars searching for a place to park takes about $30 \%$ of the whole traffic cycling in the city (Parking Network, n.d.). This means that about $1 / 3$ of the whole number of vehicles "overwhelms" traffic just to find a place to park. Another issue is uncontrolled parking, which means that parked vehicles occupy lanes which can be utilized for permitting traffic. In order to reduce the contribution of parking, it is essential to make it controlled.

Parking is an acute challenge for the city of Tbilisi. After the collapse of Soviet Union, the urbanization degree of Tbilisi went and is still going up and up. At the same time, there exists no clear transportation strategy, that includes parking in particular; Until late 2010s city hall officials did not use proper parking strategy as a mean to manage congestion and encourage public transportusage over personal vehicles (Tbilisi SUTs, 2015). Until recently parking was free of charge anywhere in Tbilisi; sidewalks were and still are crowded by vehicles everywhere in the city. The study "Consulting Services for Organization of a Transportation Household Survey in Tbilisi Metropolitan Area" conducted in 2016 by Systra LLC shows, that 29\%, almost 1/3 of drivers have problem of parking at work/study areas. The study also illustrated that $96 \%$ of all city parking is completely free at night.

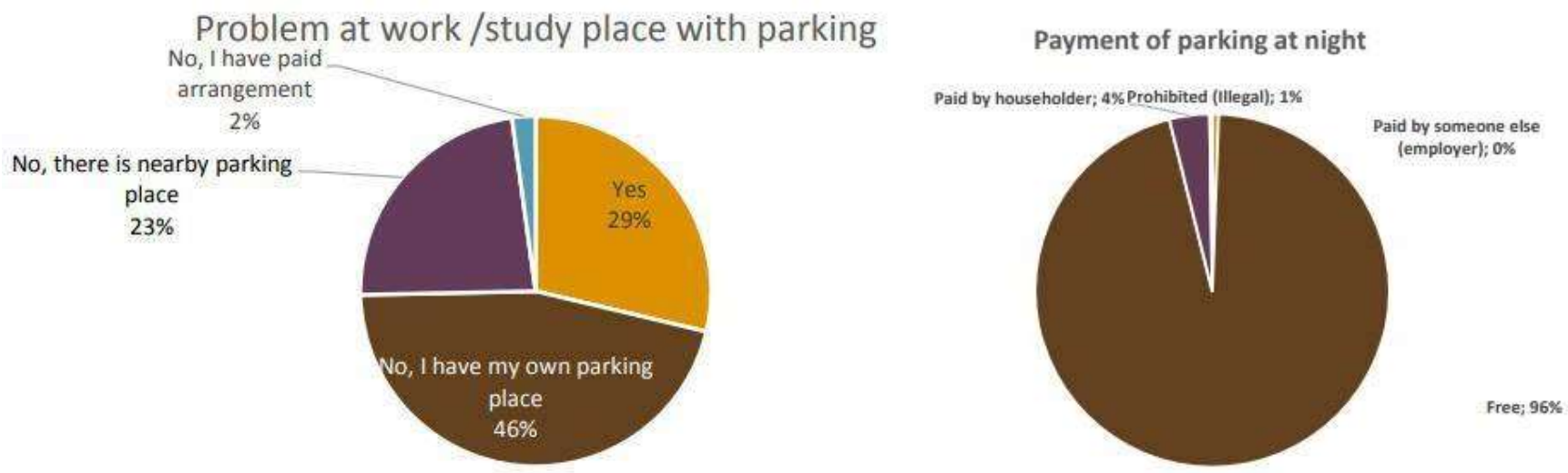

Figure 3. Source: Consulting Services for Organization of a Transportation Household Survey in Tbilisi Metropolitan Area, Systra LLC.

Received II November 20Z1; Received in revised form II November 20ZI; Accepted IZ December 20Z1;

Available online 28 December 2021;

doi: 10.46291/ICDNTECHvol5iss4pp|D-17 
As a response to the parking issue, Tbilisi City Hall introduced zonal hourly parking in 2019 (Municipal Services Development Agency, n.d). Before that the only parking strategy available inthe city was annual ticket for 50 GEL, which allowed drivers to park practically anywhere anytime.Zonal hourly parking means that while parking at some specific zones, a driver must pay hourly for the lot. This parking strategy pricing is usually applied at busy, crowded streets, which would simply not be able to endure demand in case of charge-free parking. Since this type of parking is quite expensive to use for a whole day, it discourages e.g., employees to drive at work, or studentsto drive at universities with their private cars. Currently, hourly rate for category A vehicle is 1 GEL hour (first 15 minutes in 4 zones is free). Zonal hourly parking is free for the local residents (in $100 \mathrm{~m}$ radius) and citizens with disabilities. The payment can be performed via mobile app, a paybox, or website (Tbilisi City Hall, 2020).

Another parking solution is underground parking. It frees up a significant amount of space, thus easing the burden of already crowdy streets. Consequently, it provides more parking lots than zonalhourly parking is capable of. However, from financial point of view, it is much more difficult andexpensive to implement, compared to the former, which should be taken into account when making financial decisions. As for Georgian experience, underground parking is mostly the case under large shopping malls or residential buildings. It was introduced in Georgia much earlier than hourlyparking; thus, it is more familiar for the local population.

\section{COMPLETE STREET MODEL}

While talking about congestion, it is crucial to understand that the problem can be translated into simple economic terms: demand is much higher than supply. The number of cars demanding a specific segment of a road at a specific time is much higher than the road is capable of offering. Considering this, incorporating different modes of mobility all together is a wise solution. This is exactly what a complete street model is about. Complete street is a model which incorporates infrastructure for multiple types of transportation, including walking (Burlacu, 2012). In particular, complete street model includes wider sidewalks, crosswalks with pedestrian refuge islands, curb cuts and ramps, dedicated bus lanes and shelters, bike paths, center left turn lanes, lower traffic speed.

While old-school conventional planning was fully oriented on motor vehicles, and especially personal automobiles, comprehensive multi-modal planning suggests higher involvement of various means of relocation (Litman, 2015). Although conventional planning was oriented on reaching a destination as fast as possible, current reality shows that such radically straightforward approach is not a solution for contemporary challenges, considering the population and vehicle growth in the world (Litman, 2015). Besides, streets planned by conventional models often lack connectivity. This can be caused by an absence of elements such as bike lanes, pedestrian crosswalks, sidewalks, etc. Generally speaking, complete street model contributes to trafficcongestion mitigation process in a way that this model is an optimal decision in terms of effectiveusage of the resources (Burlacu, 2012). It allows a street designed in a complete mode to move more people more effectively, compared to the same street designed in incomplete mode (Viriyincy, n.d.). Considering the distribution of all the modes of transport and some compromisesmade not in favor of private automobiles, average speeds of complete streets are relatively low (Litman, 2015). However, it is noteworthy that traffic efficiency is not only about high speeds. Moreover, considering the fact that average speeds at incomplete streets during peak hours are significantly lower than complete street speeds, and congestion is usually quite high scale, it is wiser to compromise and get a more stable, smooth flow.

From 2018 to 2020 one of the largest avenues of Tbilisi, Ilia Chavchavadze ave. was renovated andtransformed into a complete street. All the elements of a complete street, including Reversed bus- lanes (for more effectiveness), Crosswalks with pedestrian islands, Bike paths, Ramps, Broad sidewalk were constructed and successfully commissioned.

\section{PUBLIC TRANSPORTATION}

According to the most recent study of Tbilisi transport mobility, conducted in 2016, the market share for public transport has decreased by almost 10\% during the period of 2011-2016 with the contrast of increasing private car 
market share by $11 \%$. Therefore, Tbilisi City Hall decided to begin the campaign towards the discouragement of private car ownership. As a result, in the course of Tbilisi Sustainable Urban Transport (SUT) strategy public transport development holds one of the major shares of the planned tasks.

In fact, since 2015, during immediate and medium phases of this multimodal strategy, development in the public transport sector is observable. There have been several major reforms. In 2016, old buses that were not able to provide satisfactory service were replaced by newly purchased modern busses. Additionally, during 2019-2021 dedicated bus lanes have been added to two of the most congested streets of the city. Both of them are also reversed bus lanes, which means that buses travel in the opposite direction of the flow. The total distance of added bus lanes is about $8 \mathrm{~km}$. Moreover, in 2021 existing "Marshrutkas" were renewed. In addition to providing better service to customers the new "Marshrutkas" are integrated in the central public transportation system along with metro and busses; they also utilize dedicated bus lanes and serve as a minibus that holds only16 passengers.

Although it does not belong to the Tbilisi SUT strategy, when addressing advances in public transportation newly added metro station should be mentioned. Its design project dates back to 1985 , however after on and off construction phases was finally finished and opened in 2017 . It is a $2.6 \mathrm{~km}$ addition to Tbilisi underground metro network (Tbilisi City Hall, 2015).

Unfortunately, no recent surveys have been found in order to analyze how these and other reformsdiscussed in the paper have improved the market share for public transportation. In fact, the only mobility survey available was conducted in 2016 and it must be updated regularly in order to be able to define whether implemented solutions are effective or not.

\section{WORLD PRACTICES THAT COULD BE INTRODUCED IN TBILISI, GEORGIA}

\section{Reversible Lanes}

The directional demand on different roads and highways in urban areas is changing drastically throughout the day; in the morning, traffic jams are emerged because a major part of the city's workforce is rushing towards the business center, while directions to suburbs and/or residential areas are more congested and cause long delays during the evening hours. One commonly used practice for balancing directional demand depending on the period of the day is introducing reversible lanes or tidal flow as referred to by the World Road Association (n.d.). Other applications of reversible lanes include road maintenance works or vehicle accidents obstructing traffic flow. The working principle behind the reversible lanes is that specific roads permit vehicles to pass in one direction during the morning peak hours and operate in the opposite direction during evenings. With the goal of providing increased directional capacity, two-way roads could be transformed intoone-way roads, the direction of vehicle movement could be reversed on single-way roads, or middlelanes could be "borrowed" from the non-peak direction.

While deciding between different solutions to traffic congestion problems real case studies could come in handy. One such case study on the implementation of reversible lane networks on severalmajor arteries of Santiago, Chile, in 2001 (Bull, 2003) illustrates the extent of effectiveness of thetidal flow as a solution to provide increased capacity for directional peak-period flow. The average of $43 \%$ decrease in travel time was achieved with introducing reversible lanes.

However, switching directions needs to be conducted properly and carefully since it could cause confusion among drivers and could result into an increased number of car accidents, which not only becomes the source of the longer delays, but also endangers safety. Common practices for regulating traffic on reversible roads include the utilization of special signs indicating the current direction of the flow or operating with a predetermined schedule for convenience purposes (WorldRoad Association, n.d.).

Directional peak hour demand is present in Tbilisi mainly on the roads that are connecting suburbanareas to the city center. For example, Sheshelidze st. is one of the possible locations reversible lanes could be introduced. It is a 4lane road, 2 lanes in one direction and 2 in the opposite, and most importantly it does not have a physical barrier separating the flow directions. Besides, the traditional purpose of regulating peak hour directional demand, reversible lanes could also be utilized in Tbilisi, Georgia for the sake of gathering data for mobility studies. For example, if major 2-way streets were transformed into a 1-way street throughout the entire day, the number of vehicles utilizing that road during morning and evening hours could be calculated. This data wouldthen be useful for 
working on Tbilisi Sustainable Urban Transport Strategy and developing solutions to provide appropriate road capacity.

\section{ROAD PRICING}

Roads are providing service for motorists by letting them transfer from one place to another; thus, it is only natural in the contemporary capitalist world to set a price for using them. Road pricing implies imposing fees for entering or circulating specific roads or networks of roads, especially during peak-hour periods when high demand on that particular area results in heavy congestion and extremely long delays. However, collecting the fees and effectively controlling the violations while not creating long queues with manual payments at gantries requires electronic solutions which areconnected to tracking driver's locations, thus, raising privacy issues.

Regardless of the above-mentioned challenges, there are several practical methods for setting prices on roads successfully operating in different cities around the world. According to The Institute of Transportation and Development Policy (2016), the first road pricing scheme as a solution for controlling traffic flows was implemented in Singapore in 1975. At first, the manual system of Area Licensing Scheme (ALS) was introduced, which implied paying for a license that would grant the motorists access to specific roads controlled at monitoring units at the entrances. However, later Electronic Road Pricing (ERP) was implemented; this scheme operates on a cordon as well as point basis and charges different amounts of fee for utilizing different roads at varying times throughout the day. The working principle of ERP includes an in-vehicle unit with an integrated smart card that has to be installed in every vehicle (The Institute of Transportation and Development Policy, 2016). This unit receives information about the location of vehicle from satellite and automatically calculates the distance covered in the priced zone. The unit deducts appropriate amount of fee from the smart card and sends the transaction to central computer system via cellular communication. The system also has solution for controlling violations. Roadside cameras capture the images of every vehicle passing, sends the pictures of violators to the central system and immediately deletes all other images (Tan, 2013). Results of incorporating ALS and ERP systems in Singapore include a significant increase in the usage of public transportation, maintaining optimal speeds during peak-hour traffic flows, and reductions in carbon dioxide emissions.

Tbilisi, Georgia could use Singapore example and introduce road pricing to some of the most congested streets in the city-center. As Tbilisi becomes more and more congested with the numbervehicles daily, implementing road pricing would discourage citizens from utilizing personal cars.

Moreover, since Georgia is a developing country collecting funds for mobility plans and transportation system is also very crucial aspect to consider while deciding between solutions. Roadpricing promises accumulation of budget for improvement of city's transportation network.

\section{RESULTS}

Implementing Reversable lanes and Road Pricing will benefit the correct development of Tbilisi in terms of transportation.

\section{CONCLUSION}

In conclusion this paper discusses traffic congestion problems and efficient ways to deal with it inTbilisi, Georgia. It presents solutions already implemented in Tbilisi, such as complete street model, smart traffic light system, and parking. The paper illustrates reversible lanes and road pricing as possible solutions to be implemented. Noteworthy, Tbilisi is still a developing city and is actively working for bettering transportation systems. There is a lack of mobility studies in the city, the current most recent one is dated back to 2016. Since then, in the course of Tbilisi Sustainable Urban Transportation strategy many reforms have been taken for upgrading and repairing transportation system and its infrastructure. Consequently, updating existing mobility studies and initiating such surveys on the roads connecting city centers to the surrounding constantly evolving suburban areas are of crucial importance for evaluating existing solutions andadjusting them to the needs of citizens of Tbilisi.

Received I0 November 2021; Received in revised form II November 20ZI; Accepted I2 December 20Z1;

Available online 28 December 2021;

doi: 10.46291/ICDNTECHvol5iss4pp|D-17 


\section{REFERENCES}

Bretherton R.D. (1989) Scoot Urban Traffic Control System-Philosophy and Evaluation, Retrieved from https://www.sciencedirect.com/science/article/pii/S1474667017526762

Bull A. (2003) Traffic Congestion, the problem and how to deal with it, United NationsPublication. Retrieved from https://repositorio.cepal.org/bitstream/handle/11362/37898/1/LCG2199P_en.pdf

Burlacu A. (2012, November) Complete Streets Design Concept, Retrieved from https://www.researchgate.net/publication/340394318_Complete_Streets_design_concept

Business Media Georgia, August 12, 2020, "Smart" Transportation System to be implemented inTbilisi, Retrieved from https://bm.ge/ka/article/tbilisshi-chkviani-satransporto-sistema- dainergeba-/62008/

Giely J. M., December 2015, Tbilisi Sustainable Urban Transport Strategy, Retrieved from http://mdf.org.ge/storage/assets/file/documents\%202016/murtazi/Strategic\%20Paper\%20

Report\%20PDF\%20Geo(18_03_2016)/Strategic\%20Paper\%20Report\%20PDF\%20Geo.p df

Highway Traffic Management, (n.d.), Retrieved from https://rno-its.piarc.org/en/network-control- trafficmanagement-traffic-control-measures/highway-traffic-management Institute of Transportation Development Policy, (2016, May 18). The Case of Electronic Road Pricing. Retrieved from https://development.asia/case-study/caseelectronic-road- pricing

Litman T. (2015, August 24) Evaluating Complete Streets, Victoria Transport Policy Institute. Retrieved from https://vtpi.org/compstr.pdf

Municipal Services Development Agency, n.d., Zonal Hourly Parking for Mobile Application, Retrieved from https://parking.tbilisi.gov.ge/assets/files/zonal_instructions/zonalur- saatobrivi\%20parkireba_mobail.pdf

Robertson D. I., 1986, Research on the TRANSYT and SCOOT Methods of Signal Coordination, Retrieved from https://citeseerx.ist.psu.edu/viewdoc/download?doi=10.1.1.417.7154\&rep=rep1\&type=pd f

Siradze N. (2018, May 29) Transportation and Smart Mobility Systems in Tbilisi, Retrieved from https://iglus.org/transportation-and-smart-mobility-systems-in-

tbilisi/?fbclid=IwAR2Pv0cqAY6LttsOA7ZmOcVAAM8ehL19BjRCR7ZNiem20gXNZ5XOGparPQg

Steg L. (2003) Can Public Transport compete with the private car? Department of Psychology, University of Groningen, Groningen, The Netherlands Retrieved from https://doi.org/10.1016/S0386-1112(14)60141-2

Systra LLC, August 5, 2016, Consulting Services for Organization of a TransportationHousehold Survey in Tbilisi Metropolitan Area

Tan, Ch., (2013, November 13), ERP II Tender May be Called in Early 2014. Retrieved from https://www.straitstimes.com/singapore/erp-ii-tender-may-be-called-in-early-2014

Tbilisi City Hall, (2015, July 28), Construction of Metro station "University" has begun in Tbilisi. Retrieved from https://tbilisi.gov.ge/news/1361?lang=ge

Received II November 20Z1; Received in revised form II November 20ZI; Accepted IZ December 20Z1;

Available online 28 December 2021;

doi: 10.46291/ICTNTECHvol5iss4pp|D-17 